\title{
IDENTIFIKASI DAN APLIKASI PENGENALAN SPEKTRUM BUNYI GAMELAN MENGGUNAKAN JARINGAN SYARAF TIRUAN PADA MATLAB
}

\author{
Oleh : \\ Eko Ariyanto ${ }^{1}$ dan Farid Samsu $\mathbf{H}^{2}$
}

\begin{abstract}
ABSTRAK: Gamelan merupakan salah satu alat musik tradisional dari pulau Jawa. Seperangkat gamelan terdiri dari berbagai macam alat musik yang dimainkan secara bersamasama. Karena perpaduan antara bunyi gamelan satu dengan bunyi gamelan yang lainnya menggambarkan keselaraasan dalam kehidupan bermasyarakat. Namun seiring berjalannya waktu, peminat gamelan semakin sedikit dan orang pembuat gamelan juga semakin sulit dijumpai.Gamelan yang digunakan dalam penelitian ini yaitu: Gong, Kempul, Kenong dan Bonang Penerus. Bunyi gamelan akan diidentifikasi dengan caramencari frekuensi-frekuensi bunyi gamelannya. Dengan menggunakan metode Fast Fourier Transform (FFT) suatu bunyi yang berdomain waktu dapat diubah menjadi domain frekuensi dengan salah satu software Matlab.Proses dalam jaringan syaraf tiruan Backpropagation ini menggunakan jumlah neuron yang bervariasi, diantaranya: 70, 80, 90, 100 dan 110 untuk mengetahui keakuratan jaringan dalam mengenali data yang diujikan. Hanya jumlah neuron 110 lah yang dapat mengenali data pengujian sebesar 99\% untuk data pengujian pelatihan dengan MSE 0.0001233 pada epoch ke 1000. Maka hasil dalam penelitian ini jaringan dapat mengenali data pengujian dengan benar. Sehingga mengidentifikasi spektrum bunyi menggunakan jaringan syaraf tiruan dapat digunakan untuk mengenali berbagai bunyi gamelan bahkan bunyi yang lainnya.
\end{abstract}

Kata Kunci: Gamelan, Bunyi, Fast Fourier Transform (FFT), Frekuensi, Jaringan Syaraf Tiruan, Backpropagation, Matlab.

\begin{abstract}
ABSTRACK: Gamelan is a traditional music instrument of the island of Java. A set of gamelan consists of various kinds of musical instruments being played together. Due to a combination of sounds gamelan with the sound of the gamelan others describe harmony in social life. But over time, the less the gamelan enthusiasts and the instrument maker is also increasingly difficult to find. Gamelan used in this study are: Gong, Kempul, Kenong and Bonang Penerus. The sound of the gamelan will be identified by looking for gamelan sound frequencies. By using the Fast Fourier Transform (FFT) has a sound that can be converted into time domain frequency domain with one of the Matlab software. The process in this Artificial neural network backpropagation method using varying number of neurons, including: 70, 80, 90,100 and 110 to determine the accuracy of the data network in recognizing tested. 110 was the only number of neurons that can recognize $99 \%$ of the test data to test data training with MSE 0.0001233 at epoch to 1000 . So the results of this research network can recognize the test data correctly. Thus identifying sound spectrum using artificial neural networks can be used to recognize the various sounds of gamelan sound even more.
\end{abstract}

Keywords: Gamelan, Sound, Fast Fourier Transform (FFT), frequency, Artificial Neural Network, Backpropagation, Matlab.

1 Mahasiswa JurusanFisika, Fakultas Sains dan Teknologi, UIN Maliki Malang (E-mail: ecco.mahera@gmail.com)

${ }^{2}$ Staf Pengajar pada Jurusan Fisika, Fakultas Sains dan Teknologi UIN Maliki Malang 


\section{PENDAHULUAN}

Pada zaman serba modern seperti pada saat ini, warisan budaya semakin tergeser dengan adanya teknologi canggih. Bahkan sudah diambil alih oleh bangsa lain, karena generasi penerusnya sudah sedikit yang tertarik dengan budanya sendiri.Salah satu unsur yang ada di seni musik nusantara itu adalah gamelan, yang didalamnya terdiri dari sekelompok orang yang melakukan aktivitas bernyanyi juga memainkan musik.Perkembangan gamelan jawa pada mulanya pertama kali diperkenalkan oleh wali songo untuk membantu menyebarkan agama islam di nusantara khususnya pulau jawa. Para wali tersebut menggunakan gamelan sebagai daya tarik agar masyarakat mau masuk islam dan datang ke Masjid untuk melakukan ibadah [8].

Kesenian gamelan merupakan salah satu kesenian masyarakat Jawa yang sudah ada sejak lama, dengan berbagai alat musik seperti kendang, kempul, dan gong.Pertunjukkan gamelan ini sudah jarang ditemukan, karena sudah tergerus dengan masuknya budaya asing. Selain itu orang yang pembuat sudah semakin sedikit jadi kemungkinan besar warisan budaya ini akan lenyap di bangsanya sendiri. Seperangkat gamelan terdiri dari berbagai jenis alat musik dan memiliki bunyi yang berbeda-beda.

Bunyi merupakan getaran yang dihasilkan oleh benda mati sedangkan suara merupakan getaran yang dihasilkan oleh getaran (bunyi) yang keluar dari mulut atau dihasilkan oleh makhluk hidup. Namun dari sudut fisika, bunyi maupun suara keduanya sama, oleh karena keduanya sama-sama merupakan getaran[4].Bunyi adalah suatu bentuk gelombang longitudinal yangmerambat secara perapatan dan perenggangan terbentuk oleh partikel zatperantara serta ditimbulkan oleh sumber bunyi yang mengalami getaran[3].

Bunyi memiliki suatu ciri khas yaitu salah satunya berupa frekuensi. Satuan frekuensi adalah Hertz, diambil dari penemunya yaitu Heinrich Rudolf Hertz seorang fisikawan dalam bidang elektromagnetik.Bunyi yang kita kenal, berada pada frekuensi pendengaran yaitu antara $20 \mathrm{~Hz}$ sampai $20.000 \mathrm{~Hz}[10]$.FFT (Fast Fourier Transform) adalah suatu metoda untuk mentransformasikan sinyal bunyi menjadi sinyal frekuensi, artinya proses perekaman bunyi disimpan dalam bentuk digital berupa gelombang spektrum bunyi berbasis frekuensi[1].

Jaringan Syaraf Tiruan (Artifical Neural Network) atau disingkat JST adalah sistem komputasi dimana arsitektur dan operasi diilhami dari pengetahuan tentang sel syaraf biologi di dalam otak .Jaringan syaraf tiruan merupakan salah satu representasi buatan dari otak manusia yang selalu mencoba mensimulasikan proses pelatihan pada otak manusia tersebut. Istilah buatan disini digunakan karena jaringan syaraf ini diimplementasikan dengan menggunakan program komputer yang mampu menyelesaikan sejumlah proses perhitungan selama proses pelatihan. Pada jaringan syaraf, neuron-neuron dikumpulkan dalam lapisan-lapisan (layer) yang disebut lapisan neuron (neuron layers). Biasanya neuron-neuron pada satu lapisan akan dihubungkan dengan lapisan-lapisan sebelum dan sesudahnya (kecuali lapisan input dan lapisan output). Informasi yang diberikan pada jaringan syaraf dirambatkan lapisan ke lapisan, mulai dari lapisan input sampai ke lapisan output melalui lapisan yang lainnya, yang sering dikenal dengan nama lapisan tersembunyi (hidden layer) [6]. 
Proses belajar pada jaringan syaraf tiruan ditunjukkan dengan perubahan bobot penghubung antar sel jaringan syaraf. Secara sederhana, jaringan akan menemukan pasangan-pasangan yang sesuai antara masukan (input) dan keluaran (output) yang dilatihkan melalui algoritma dalam beberapa kali iterasi. Dalam pelaksanaannya akan terjadi bias atau perbedaan output yang tidak sesuai dan mengakibatkan suatu pola yang tidak dikenali oleh jaringan. Hal ini terjadi karena sampel suatu pola yang baru belum pernah dilatihkan atau tidak memiliki kemiripan dan kesamaan dengan salah satu pola data yang ada[5].Dalam jaringan syaraf tiruan, fungsi aktivasi digunakan untuk menentukan keluaran suatu Neuron. Argumen fungsi aktivasi adalah kombinasi linier masukan dan bobotnya[2].

Algoritma pelatihan Backpropagasi (Backpropagation) atau ada yang menterjemahkannya menjadi propagasi balik, pertama kali dirumuskan oleh Werbos dan dipopulerkan oleh Rumelhart bersama Mc Clelland untuk dipakai pada JST, selanjutnya algoritma ini biasa disingkat dengan BP. Algoritma ini termasuk metoda pelatihan terbimbing (supervised) dan didesain untuk operasi pada JST feed forward lapis jamak (multilayer)[7].

Pelatihan Backpropagation meliputi 3 fase.Fase pertama adalah fase maju.Pola masukan dihitung maju mulai dari Iayar masukan hingga layar keluaran menggunakan fungsi aktivasi yang ditentukan.Fase kedua adalah fase mundur. Selisih antara keluaran jaringan dengan target yang diinginkan merupakan kesalahan yang teljadi. Kesalahan tersebut dipropagasikan mundur, dimulai dari garis yang berhubungan langsung dengan unit-unit di layar keluaran. Fase ketiga adalah modifikasi bobot untuk menurunkan kesalahan terjadi[9].

Ketiga fase terebut diulang-ulang terus hingga kondisi penghentian dipenuhi.Umumnya kondisi penghentian yang sering dipakai adalah jumlah iterasi atau kesalahan. Iterasi akan dihentikan jika jumlah iterasi yang dilakukan sudah melebihi jumlah maksimum iterasi yang ditetapkan, atau jika kesalahan yang terjadi sudah lebih kecil dari toleransi yangdiijinkan[9].Fungsi kinerja yang sering digunakan untuk backpropagationadalah Mean Square Error (MSE), yang dimana fungsi ini akanmengambil rata-rata kuadarat error yang terjadi antara output jaringan dan target.

Langkah-langkah penelitian yang digunakan adalah pertama, Sistem pengambilan datanya pada penelitian ini diawali dengan pengukuran diameter dari tiap-tiap alat musik gamelan.Selanjutnya dilakukan perekaman bunyi langsung dari alat musik gamelannya tepat dipukul ditengah-tengahnya memakai mikrofon Philips SHM1000 PC.Penagkapan bunyi menggunakan speaker yang terdapat pada laptop dibantu dengan menggunakan perangkat lunak Audacity.

File-nya disimpan dalam format .wav, karena Matlab hanya bisa mengolah format bunyi dalam bentuk tersebut.Setelah itu sinyal bunyi ditransformasikan dengan menggunakan Fast Fourier Transform (FFT), untuk mengubah sinyal bunyi yang domain waktu menjadi domain frekuensiSetelah diperoleh sinyal yang berdomain frekuensi selanjutnya mulai mencari frekuensi yang dominan. Sehingga nantinya ini yang akan menjadi nilai masukan dari jaringan syaraf tiruan.

Untuk Jaringan Syaraf Tiruan (JST) backpropagation yaitu memasukkan nilai hasil pengeplotan grafik yang berupa frekuensi sebagai nilai masukan. Nilai-nilai tersebut 
sebagai data latih. Gunanya melatih JST backpropagation, agar jika ada data bunyi baru yang telah melewati tahap analisis seperti diatas, dapat dilakukan pencocokan ciri atau identifikasi (pengujian), yang nantinya akan memberikan suatu keluaran, apakah karakteristik bunyi tersebut sama atau tidak.

\section{HASIL DAN PEMBAHASAN}

Pada penelitian ini bunyi gamelan jawa yang digunakan adalah bunyi gamelan jawa yang telah direkam dengan bantuan mikrofon yang terhubung dengan laptop dan disimpan secara langsung dalam bentuk audio yang berformatkan .wav. Selanjutnya pengambilan datanya, dalam perekaman pengambilan bunyi yang harus dipukul yaitu tepat ditengahtengah pencon-pencon (pencu) pada masing-masing alat. Karena ditengah-tengah pencon itulah sumber bunyi yang paling bagus. Software yang dibutuhkan dalam proses perekaman ini yaitu "Audacity".

Setelah software dibuka maka dalam bersamaan gamelan dipukul dan di klik tombol rekam sampai berhenti berbunyi dan di klik stop. Selanjutnya file tersebut di save dalam bentuk format .wav (waveform audio format), karena program Matlab hanya bisa dimasuki audio yang berformatkan .wav. Pada masing-masing alat diperlukan data minimal $35 \mathrm{x}$ pukulan. Sebelum melakukan perekaman, mikrofon yang digunakan harus berada disamping bawah gamelannya. Agar bunyi yang terekam tidak mengalami noise terlalu banyak yang diakibatkan oleh pemantulan bunyi gamelannya. Setelah data diperoleh dan disimpan dalam bentuk file audio yang berformatkan .wav, selanjutnya data tersebut diolah menggunakan Matlab. Dari file audio tersebut kita bisa melihat spektrumnya yang masih berupa domain waktu. Berikut gambar hasil rekaman yang ada pada software Audacity dan file audio yang telah dipanggil pada Matlab:

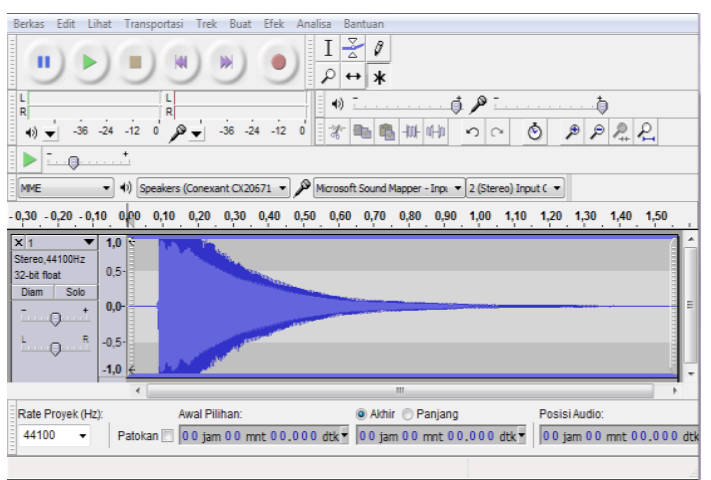

Gambar 1. Hasil Rekaman Software Audacity

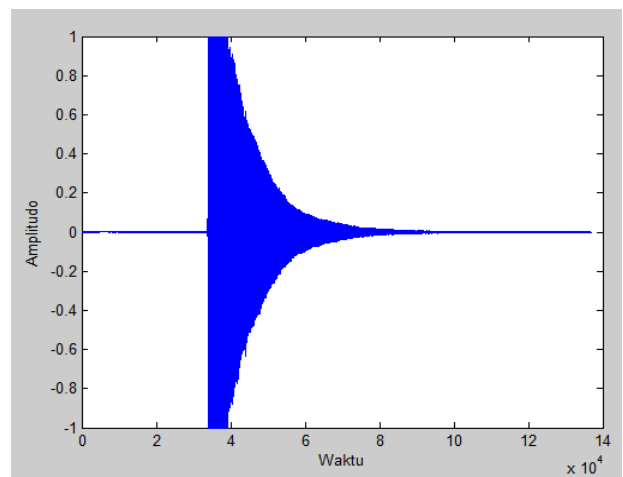

Gambar 2. Spektrum Bunyi dalam Domain Waktu

Spektrumyang masih dalam domain waktu tersebut kemudian ditransformasikan menjadi domain frekuensi dengan metode FFT (Fast Fourier Transform). Sebelum ditransformasikan ke metode FFT, data tersebut diabsolutkan terlebih dahulu, agar data yang akan diperoleh tidak ada yang bernilai negatif. Selanjutnya untuk mengetahui berapa frekuensi yang dominan atau yang paling tinggi agar lebih jelas nilai frekuensinya maka dilakukan pembesaran sampai nilai frekuensinya didapat dengan jelas. Berikut gambar yang sudah dalam domain frekuensi dan gambar yang telah melalui proses pembesaran 10x dibawah ini: 


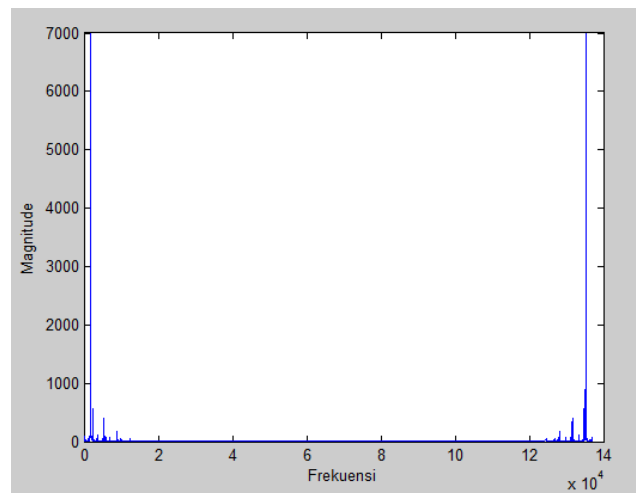

Gambar 3. Spektrum Bunyidalam Domain Frekuensi

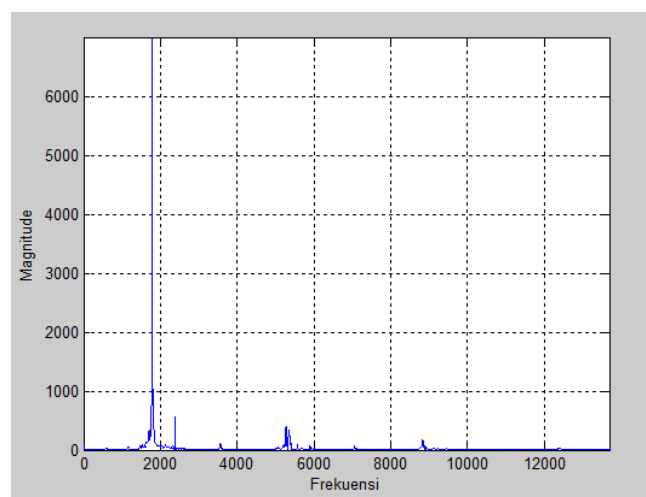

Gambar 4. Domain Frekuensi dengan perbesaran $10 \mathrm{x}$

Nilai tersebut dimasukkan dalam tabel yang sebelumnya telah dibuat dan menjadi nilai inputan pada jaringan syaraf tiruannya. Untuk file audio lainya dapat dilakukan seperti cara yang diatas sampai 35x tiap-tiap alat musik yang diteliti. Berikut gambar tabel hasil pengambilan data yang akan menjadi inputan pada jaringan syaraf tiruan backpropagation.

Setelah data sebagai masukantelah didapatkan, selanjutnya digunakan untuk merancang jaringan syaraf tiruannya untuk pelatihan maupun pengujian data pelatihan (training). Arsitekturjaringan syaraf tiruan yang digunakan adalah jaringan syaraf tiruan dengan algoritmabackpropagation yang merupakanalgoritma pelatihan yang terawasi. Algoritma backpropagation menggunakan error output untuk mengubah nilai bobotbobotnya dalam arah mundur (backward). Untuk mendapatkan nilai error ini tahap perambatanya maju (forward propagation) harus dikerjakan terlebih dahulu. Pada saat perambatan maju, neuron-neuronakandiaktifkan dengan menggunakan fungsi aktivasisigmoidbiner.

Dalam proses pelatihanjaringan syaraf tiruan, pada tahap feedforward, setiap unit masukan menerima sinyal dan menyebarkan sinyal tersebut ke setiap unit pada lapisan tersembunyi setelah dikalikan dengan bobotnya masing-masing melalui hubungan antara lapisan masukan dengan lapisan tersembunyi. Seluruh sinyal yang masuk ke setiap unit pada lapisan tersembunyi akan dijumlahkan dan diproses dengan fungsi aktivasi sehingga akan dihasilkan sinyal keluaran yang langsung disebar ke setiap unit pada lapisan keluaran.

Setelah semua data yang telah didapatkan sudah dilatih dengan metode Backpropagation, selanjutnya data tersebut dilakukan pengujian.Pengujian dalam penelitian ini menggunakan data yang telah didapatkan sebelumnya yaitu data frekuensi gong, kempul, kenong dan bonang penerus dan menggunakan data baru pada frekuensi dari alat musik gamelan yang lainnya.

Hasil dari pelatihan Jaringan Syaraf Tiruan pada jaringan feedforward didapatkan bobot-bobot yang baik karena dalam pelatihan dilakukan pengaturan bobot. Selama proses pelatihannya, bobot-bobot telah diatur secara efisien untuk meminimalisir Mean Square Error (MSE). Bobot-bobot hasil dari pelatihan ini nantinya yang digunakan untuk mengatur bobot pada jaringan untuk pengujian data latih (training) dan data uji (testing). Jaringan Syaraf Tiruan ini menggunakan 1 lapisan masukan, 2 lapisan tersembunyi dan 1 keluaran.Sedangkan jumlah neuron pada lapisan tersembunyi dibuat bervariasi yaitu 80 , 
90, 100, 110 dan 120.Jumlah neuron ini dibuat bervariasi bertujuan untuk menemukan waktu yang paling efektif dan hasil terbaik dalam proses pelatihan. Untuk penentuan jumlah neuron pada lapisan tersembunyi ini dilakukan secara eksperimental (random), karena dalam menentukan jumlah neuron ini belum ada standar yang digunakan sebagai acuannya. Berikut gambar arsitektur jaringan backpropagation dibawah ini:

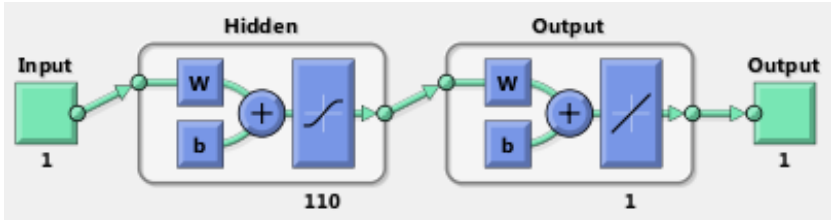

Gambar 5. Jaringan Backpropagation

Fungsi aktivasi yang digunakan pada lapisan tersembunyi dan lapisan keluaran adalah fungsi sigmoid biner, karena fungsi aktivasi sigmoidbiner ini mempunyai rentang masukan dari $-\infty$ sampai $+\infty$ namun keluarannya dalam rentang 0 sampai 1 . Sedangkan fungsi transfer pada pelatihan jaringan yang digunakan adalah trainlm karena fungsi pelatihan ini yang paling cepat dalam proses pelatihannya.

Dalam jaringan syaraf tiruan backpropagation ada 2 faktor yang mempengaruhi keberhasilan dalam pelatihan dam pengujian, diantaranyaepoch dan neuron. Kombinasi nilai epoch dan neuron secara random ini akan melatih jaringan sampai proses pelatihannya berhenti dengan sendirinya. Dalam kondisi ini jaringan sudah dianggap pintar apabila dalam kondisi ini menghasilkan nilai Mean Square Error (MSE) yang paling kecil dan yang paling mendekati target. Karena fungsi Mean Square Error (MSE) ini akan mengambil rata-rata kuadrat error yang terjadi antara keluaran jaringan dengan target atau rata-rata selisih antara target latih dan target uji.

Setelah Jaringan Syaraf Tiruan telah dilatih, selanjutnya waktunya pengujian. Pengujian Jaringan Syaraf Tiruan disini menggunakan 2 data pengujian. Yang pertama, pengujian menggunakan data pelatihan untuk mengetahui keberhasilan dari Jaringan Syaraf Tiruan dalam mengenali dan mengidentifikasi data pelatihan. Dalam pengujian ini semua data pelatihan diujikan secara bersama-sama dan menggunakan perbedaan jumlah neuron pada lapisan tersembunyi, sehingga dalam pengujian data pelatihan ini menghasilkan nilai MSE yang paling kecil. Dari hasil pengujian data pelatihan ini didapatkan nilai MSE sebesar 0.0001233 pada epoch ke 1000 dengan jumlah neuron 110, sedangkan target yang digunakan adalah nilai MSE yang mendekati nol yaitu 0.0001 . Maka jaringan sudah dapat digunakansebagai pengujian data latih. Berikut untuk tampilan grafik training data latih tersebut dapat dilihat pada gambar dibawah ini:

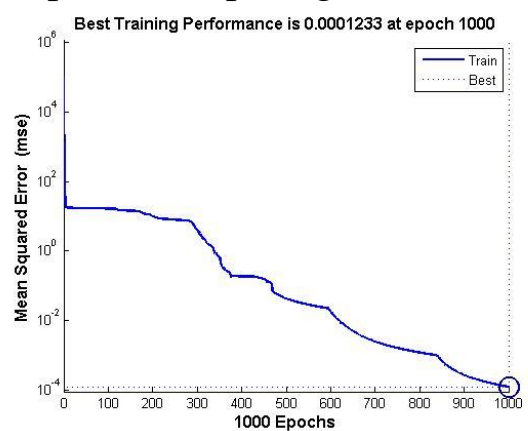

Gambar 6.Grafik Performa Jumlah Neuron 110 
Setelah semua pelatihan dan pengujian baik data latih maupun data baru sudah selesai, selanjutnya hasil tersebut diterapkan pada GUI (Graphical User Interface) agar mempermudahkan dalam penggunaan aplikasi jaringan syaraf tiruan backpropagationpada matlab untuk mengidentifikasi dan pengenalan spektrum bunyi gamelannya.Dalam GUI ini akan ditampilkan hasil pelatihaanya, hasil pengujiannya, dan aplikasi bunyi gamelannya serta petunjuk-petunjuk dan keterangan tentang gamelannya.Berikut tampilan GUI pada gambar dibawah ini:

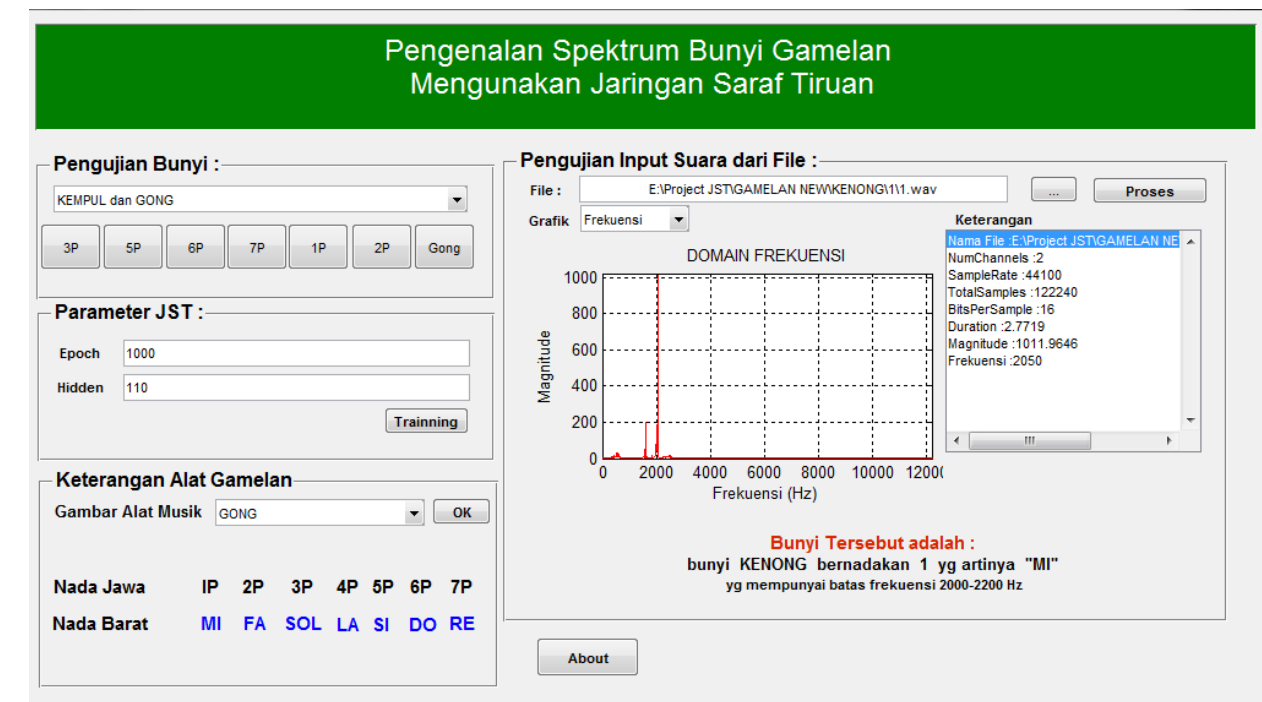

Gambar 7. Tampilan GUI Jaringan Syaraf Tiruan untuk Aplikasi Pengenalan Spektrum Bunyi Gamelan

Pada tampilan GUI tersebut terdiri dari 4user, user pertama digunakan untuk aplikasi memainkan bunyi gamelannya. Dalam user ini terdapat menu untuk memilih jenis alat musik gamelan dan tombol untuk memainkan bunyi gamelannya, apabila salah satu tombol untuk memainkan bunyi ini ditekan maka akan keluar bunyi sesuai nada aslinya dan kemudian akan muncul garfik serta keterangan dari bunyi tersebut.

Sedangkan user kedua digunakan untuk pelatihan jaringan syaraf tiruannya. Dalam user ini terdapat 2 parameter pelatihan jaringan syaraf tiruannya yaitu "epoch" dan "hidden". Parameter-parameter tersebut digunakan untuk melatih jaringan syaraf tiruan. Selain itu juga terdapat tombol "training", tombol ini digunakan untuk memulai pelatihan jaringan syarf tiruannya.

Sedangkan untuk user ketiga digunakan untuk pengujian dari Jaringan syaraf tiruannya. Dimana dalam user ini terdapat menu "browse" yang digunakan untuk mencari file audio yang berformatkan .WAV yang akan diuji kedalam sistem jaringan syaraf tiruan yang selanjutnya akan keluar bunyi dan muncul spektrumnya pada grafik serta muncul keteranganya dari file audio. Selain itu juga ada tombol "Proses" yang digunakan untuk mengeksekusi bunyi yang diuji dan kemudian muncul keterangan bunyi tersebut. Apabila nada yang diuji mempunyai nilai frekuensi yang masuk dalam range frekuensi alat gamelan maka nada tersebut diidentifikasi menjadi nada alat tersebut dan apabila nada yang diuji diluar atau tidak masuk dalam range frekuensi alat gamelan maka nada tersebut tidak dapat diidentifikasi. 
Sedangkan untuk user keempat adalah berisikan keterangan-keterangan dari alat musik gamelannya. Keterangan ini memuat gambar, ukuran dimensi, berat, dan sedikit cacatan untuk lebih mengenal alat musik gamelannya dan berisikan petunjuk dalam nada jawa ke nada barat atau modern sehingga dapat dan mudah dimainkan banyak orang.

\section{KESIMPULAN}

Dari data hasil penelitian dan pembahasan yang telah diuraikan, dapat diambil kesimpulan sebagai berikut :

1. Perancangan sistem jaringan syaraf tiruan backpropagation memberikan hasil yang memuaskan dalam proses pengenalan spektrum bunyi gamelan, hal ini disebabkan oleh jumlah neuron yang digunakan pada lapisan tersembunyi (hidden layer) tidak terbatas pada masukan yang diberikan.

2. Dalam pengujian yang menggunakan data latih tingkat keberhasilannya mencapai $99 \%$ pada jumlah neuron 110 dan didapatkan nilai MSE sebesar 0.0001233 pada epoch ke 1000, hal ini menunjukkan suatu jaringan sudah dapat mengenali spektrum bunyi gamelan dengan baik dan cerdas.

3. Pengidentifikasian spektrum bunyi gamelan dapat digunakan untuk mengetahui nadanada bunyi gamelan, sehingga nada-nada tersebut dapat dibedakan ke dalam jenisjenis alat gamelannya. Serta dapat digunakan sebagai acuan dalam membuat nada atau melaraskan bunyi gamelan, karena sampai saat ini tidak ada acuan khusus dalam pembuatan nada gamelan.

\section{DAFTAR PUSTAKA}

[1] Adler, John.dkk,. 2013. Identifikasi Suara dengan MATLAB sebagai Aplikasi Jaringan Syaraf Tiruan. Bandung: Teknik Komputer, Universitas Komputer Indonesia (UNIKOM)

[2] Agustin, Maria. 2012. Penggunaan Jaringan Syaraf Tiruan Backpropagation Untuk Seleksi Penerimaan Mahasiswa Baru Pada Jurusan Teknik Komputer Di Politeknik Negeri Sriwijaya. Semarang: Program Pascasarjana Universitas Diponegoro

[3] Doelle, L. Leslie. 1985. Akustik Lingkungan. Terjemahan oleh: Lea Prasetia. Bandung: Erlangga

[4] Gabriel, J. F. 2001. Fisika Lingkungan. Jakarta: Hipokrates

[5] Hermawan, Arief. 2006. Jaringan Saraf Tiruan, Teori dan Aplikasinya. Yogyakarta: Andi

[6] Kusumadewi, Sri. 2004. Membangun Jaringan Syaraf Tiruan Menggunakan Matlab \& Excel Link. Yogyakarta: Graha Ilmu

[7] Purnomo, Hery M.danKurniawan, Agus. 2006. Supervised Neural Networks dan Aplikasinya. Yogyakarta: Graha Ilmu

[8] Rahimsyah. 2011. Kisah Perjuangan Walisongo. Surabaya: Dua Media 
[9] Siang, J. J. 2009. Jaringan syaraf tiruan dan pemrogramannya menggunakan Matlab. Yogyakarta: Andi

[10] Sutrisno. 1979. Fisika Dasar : Gelombang dan Optik. Bandung: ITB 